\title{
Las inversiones extranjeras en el Mercosur: ¿Hacia un cambio de paradigma?
}

\author{
Foreign investments in Mercosur: Towards \\ a change of paradigm?
}

Investimentos estrangeiros no mercosul: Rumo a uma mudanca no paradigma?

Investissements etrangers dans le Mercosur:

Vers un changement de paradigme?

南方共同市场的外国投资:向范式转变?

\begin{tabular}{l|l} 
Luis Fernando Castillo & $\begin{array}{l}\text { Universidad de Buenos Aires, } \\
\text { Argañaráz }\end{array}$
\end{tabular} \mid $\begin{aligned} & \text { Argentina }\end{aligned}$

Revista Derechos en Acción ISSN 2525-1678/ e-ISSN 2525-1686

Año 4/NNo 13, Primavera 2019 (21 septiembre a 20 diciembre), 249-270

DOl: https://doi.org/10.24215/25251678e338

ORCID: https://orcid.org/0000-0001-5566-462X

Recibido: 07/06/2019

Aprobado: 25/09/2019

Resumen: La recepción de inversión extranjera directa es un punto importante en la agenda de los Estados de la Región. A iniciativa de Brasil se adoptó el Protocolo de Cooperación y Facilitación de inversiones Intra - MERCOSUR apartándose en su esquema de los tradicionales Tratados Bilaterales de Protección de Inversiones. El objetivo de este artículo es analizar brevemente el nuevo Protocolo y el camino que culminó con su firma.

Palabras claves: MERCOSUR - Inversiones extranjeras- Inversiones Intra - MERCOSUR- Acuerdos de facilitación de inversiones

1 Investigador del CONICET/UADE. Doctor en Derecho (UBA), Doctor en Ciencia Política (UB). Profesor titular de Derecho Internacional Público (UADE). Email: Icastillo@uade.edu.ar. 
Abstract: The reception of foreign direct investment is an important point on the agenda of the States of the Region. At the initiative of Brazil, the Protocol of Cooperation and Facilitation of Investments Intra - MERCOSUR was adopted, moving away from the traditional Bilateral Treaties of Investment Protection. The objective of this article is to briefly analyze the new Protocol and the path that culminated with its signing.

Key Words: MERCOSUR - Foreign Investments - Investments Intra MERCOSUR- Investments Facilitation Agreements

Resumo: A recepção do investimento estrangeiro direto é um ponto importante na agenda dos Estados da Região. Por iniciativa do Brasil, foi adotado o Protocolo de Cooperação e Facilitação de Investimentos Intra-MERCOSUL, afastando-se dos tradicionais Tratados Bilaterais de Proteção ao Investimento. 0 objetivo deste artigo é analisar brevemente o novo Protocolo e o caminho que culminou com sua assinatura.

Palavras chave: MERCOSUL - Investimentos Estrangeiros - Investimentos Intra - MERCOSUL - Acordos de Facilitação de Investimentos

Résumé: Recevoir des investissements étrangers directs est un point important à l'ordre du jour des États de la Région. À l'initiative du Brésil, le Protocole de coopération et de facilitation pour l'investissement intraMERCOSUR a été adopté, s'éloignant ainsi des traités traditionnels de protection des investissements bilatéraux. L'objectif de cet article est d'analyser brièvement le nouveau protocole et la voie qui a abouti à sa signature.

Mots clés: MERCOSUR - Investissements étrangers - Investissements Intra - MERCOSUR - Accords de Facilitation des Investissements

摘要：接受外国直接投资是该地区各国议程上的重要内容。 在巴西的倡议下, 通过了《南共市内部投资合作与便利化议 定书》, 其计划与传统的双边投资保护条约背道而驰。本文的 目的是简要分析新协议及其签署的最终路径。

关键字：南方共同市场-外国投资-内部投资-南方共同市场-投资便 利化协议。 


\section{Introducción}

Las inversiones extranjeras es un punto que ha conquistado un lugar en la agenda de América Latina, y particularmente MERCOSUR, en los últimos años. Así, se ha señalado que "el análisis de las políticas, normas y el tratamiento de las inversiones extranjeras ha sido el tema recurrente de debate para los países latinoamericanos a lo largo de su historia" (Marchini, Morales y Roffinelli 2018: 15).

Se ha considerado en relación a los tratados bilaterales de protección de inversiones (TBI) que su objetivo es "incrementar la prosperidad a través de la inversión" (Vandevelde 1988: 621). No obstante, se puede señalar que "actualmente presenciamos un debate político y académico sobre uno de los pilares ideológicos de los años noventa, que aseguraba la existencia de una relación causal entre la firma de los Tratados Bilaterales de Inversión (TBI) y el aumento en los flujos de Inversión Extranjera Directa (IED)" (Arroyo Picard y Ghiotto, 2017: 39).

En el marco del MERCOSUR, durante la década de 1990, por Decisión del Consejo Mercado Común $N^{\circ} 11 / 93$ se aprobó el Protocolo de Colonia para la Promoción y Protección Recíproca de Inversiones en el MERCOSUR, ${ }^{2}$ y por Decisión del Consejo Mercado Común No 11/94 se adoptó el Protocolo sobre Promoción y Protección de Inversiones Provenientes de Estados No Partes del MERCOSUR. ${ }^{3} \mathrm{Al}$ respecto se ha señalado que "estas Decisiones reflejaban un esquema clásico en materia de inversiones extranjeras, a tono con los postulados económicos liberales que imperaban en esos años, marcados por la finalización de la Guerra Fría" (Laborías 2018:133). Estos instrumentos jurídicos nunca entraron en vigor.

2 Firmado el 17 enero 1994. No vigente. El texto puede consultarse en http://www.sice. oas.org/trade/mrcsr/colonia/pcolonia_s.asp (última consulta 20 de julio de 2019)

3 Firmado el 5 de Mayo de 1994. No vigente. El texto puede consultarse en http://www.sice.oas.org/trade/mrcsrs/Decisions/dec1194s.asp (última consulta el 20 de julio de 2019) 
El 16 de Diciembre de 2010 mediante la Decisión del Consejo Mercado Común $\mathrm{N}^{\circ} 30 / 10$ se aprobaron las "Directrices para la celebración de un Acuerdo de Inversiones en el MERCOSUR" ${ }^{4}$ que en su punto 10 establece "Derogar las Decisiones CMC $\mathrm{N}^{\circ} 11 / 93$ y N $\mathrm{N}^{\circ} 11 / 94$ y sus respectivos Acuerdos" y se instruye al Subgrupo de Trabajo $\mathrm{N}^{\circ} 12$ "Inversiones" para que eleve al Grupo del Mercado Común una propuesta de acuerdo. Este Subgrupo "había sido creado en el año 2000 y entre sus funciones se incluyó la de analizar las dificultades que habían encontrado los Estados Partes para aprobar e implementar los textos de 1993 y 1994" (Laborías 2018:133). Finalmente, luego de arduas negociaciones, el 7 de abril de 2017 en el marco del Foro Económico Mundial que se celebró en Buenos Aires, los Ministros de Relaciones Exteriores de los países que integran el MERCOSUR adoptaron el Protocolo de Cooperación y Facilitación de las Inversiones Intra- MERCOSUR (PCFI) mediante Decisión 3/2017 del Consejo Mercado Común. ${ }^{5}$

De acuerdo a lo planteado previamente, surgen los siguientes interrogantes: 1) ¿Cómo y porqué surgieron los acuerdos sobre cooperación y facilitación de las inversiones extranjeras?, 2) ¿Cuáles son las principales disposiciones del Protocolo de Cooperación y Facilitación de las Inversiones Intra- MERCOSUR?, 3) El PCFI, ¿Implica un cambio de paradigma con respecto a los

\footnotetext{
4 MERCOSUR. Decisión MERCOSUR/CMC/DEC. N N 30/10 “Directrices para la celebración de un Acuerdo de Inversiones en el MERCOSUR". El texto puede consultarse en http://www. sice.oas.org/Trade/MRCSRS/Decisions/DEC3010_s.pdf (última consulta el 20 de julio de 2019)

5 Fue firmado por Argentina, Brasil, Paraguay y Uruguay. Venezuela está suspendido desde diciembre de 2016. Uruguay depositó el instrumento de ratificación el día 29/09/2018 y Brasil aprobó por Decreto Legislativo N ${ }^{0} 181$ del 20/12/2018 y depositó el instrumento de ratificación el 31/05/2019. Entró en vigor para estos dos países el 30/07/2019. En el Art. 26 se establece que "Entrará en vigor en 60 días después de la fecha del depósito del segundo instrumento de ratificación por parte de los estados partes del MERCOSUR, para los demás Estados Partes que lo ratifiquen con posterioridad, entrará en vigor 60 días después del depósito de cada instrumento de ratificación". Ver: http://www.mre.gov.py/tratados/ public_web/DetallesTratado.aspx?id=+uUEOsWR9wE3v91PDIXvnQ==\&em=Ic4aLYHVBOdF+k NrtEvsmZ96BovjLIzOmcrZruYPcn8= (última consulta 20 de Julio de 2019)
} 
tradicionales TBIs? En ese sentido, el objetivo de este artículo es analizar brevemente el Protocolo de Cooperación y Facilitación de las Inversiones Intra- MERCOSUR y el camino que culminó con su firma. Las respuestas a estos interrogantes planteados y el cumplimiento de los objetivos establecidos permitirán arribar a conclusiones.

\section{La ruta hacia el protocolo de 2017 y el protagonismo de Brasil}

En la actualidad, Argentina tiene vigentes $49 \mathrm{TBIs}^{6}$, Uruguay llega al número de 30 tratados en vigor ${ }^{7}$, Paraguay 21 tratados bilaterales en vigencia ${ }^{8}$, la República Bolivariana de Venezuela (suspendido en el MERCOSUR) con 25 vigentes $^{9}$, y Brasil tiene

6 Argentina tiene vigente 49 TBls con los siguientes Estados: Argelia, Armenia, Australia, Austria, Unión Económica Belga - Luxemburguesa, Bulgaria, Canadá, Chile, China, Costa Rica, Croacia, Cuba, República Checa, Dinamarca, Egipto, El Salvador, Finlandia, Francia, Alemania, Guatemala, Hungría, Israel, Italia, Jamaica, República de Corea, Lituania, Malasia, México, Marruecos, Países Bajos, Nicaragua, Panamá, Perú, Filipinas, Polonia, Portugal, Rumania, Federación Rusa, Senegal, España, Suiza, Suecia, Estados Unidos de América, Tailandia, Túnez, Turquía, Ucrania, Reino Unido, República Bolivariana de Venezuela, Vietnam. Información obtenida de la página web de UNCTAD ver: https://investmentpolicy.unctad.org/ international-investment-agreements (última consulta 20 de julio de 2019)

7 Uruguay tiene vigente 30 TBls con los siguientes Estados: Armenia, Australia, Unión Económica Belga - Luxemburguesa, Canadá, Chile, China, República Checa, El Salvador, Finlandia, Francia, Alemania, Hungría, Israel, Italia, Japón, República de Corea, Malasia, México, Países Bajos, Panamá, Polonia, Portugal, Rumania, España, Suiza, Suecia, Reino Unido, Estados Unidos de América, República Bolivariana de Venezuela, Vietnam. Información obtenida de la página web de UNCTAD ver: https://investmentpolicy.unctad.org/ international-investment-agreements (última consulta 20 de julio de 2019.)

8 Paraguay tiene en vigor 22TBIs con los siguientes Estados: Austria, Unión Económica Belga - Luxemburguesa, Estado Plurinacional de Bolivia, Chile, Costa Rica, Cuba, República Checa, El Salvador, Italia, Francia, Alemania, Hungría, República de Corea, Países Bajos, Perú, Portugal, Rumania, España, Suiza, Taiwán, Reino Unido, República Bolivariana de Venezuela. Información obtenida de la página web de UNCTAD ver: https://investmentpolicy. unctad.org/international-investment-agreements (última consulta 20 de julio de 2019).

9 La República Bolivariana de Venezuela tiene 25TBls en vigor con los siguientes Estados: Argentina, Barbados, Bielorrusia, Unión Económica Belga - Luxemburguesa, Canadá, Chile, Costa Rica, Cuba, República Checa, Dinamarca, Francia, Alemania, Indonesia, República 
firmados 14, de los cuales ninguno está en vigencia ${ }^{10}$; además firmó 8 acuerdos de cooperación y facilitación de las inversiones (solo está en vigencia el firmado con Angola) ${ }^{11}$.

De acuerdo a lo referido en la Introducción del presente artículo, existe un debate sobre la relación causal que vincula a la firma de los TBIs con el aumento de los flujos de IED (Arroyo Picard y Ghiotto, 2017: 39). En ese sentido, se puede señalar que:

En América Latina, Brasil ha sido prueba notoria de que dicha relación causal es al menos cuestionable. Efectivamente, este país es el principal receptor y emisor de IED en América Latina y no tiene ningún TBI en vigencia. Sin embargo, esta realidad ha cambiado, ya que Brasil negoció recientemente cinco tratados de inversión: Mozambique, Angola, México, Chile y Colombia, todos en el año 2015 (Arroyo Picard y Ghiotto 2017: 40).

Magdalena Bas Vilizzio relata que "cuando seis de los catorce TBI celebrados por Brasil llegaron al Congreso, el presidente Cardozo decidió formar un Grupo de Trabajo Interministerial para su análisis en profundidad" (2018: 49).

En 2002 el Grupo de Trabajo recomienda que los TBI no fueran aprobados por generar un potencial conflicto con la Constitución en materia de libre transferencia de capitales al exterior y solución de controversias con

Islámica de Irán, Lituania, Paraguay, Perú, Paraguay, Federación Rusa, España, Suiza, Suecia, Reino Unido, Uruguay, Vietnam. Información obtenida de la página web de UNCTAD ver: https://investmentpolicy.unctad.org/international-investment-agreements (última consulta 20 de julio de 2019)

10 Brasil tiene firmados 14(no en vigor) TBls con los siguientes Estados: Unión Económica Belga - Luxemburguesa, Chile, Cuba, Dinamarca, Finlandia, Francia, Alemania, Italia, República de Corea, Países Bajos, Suiza, Reino Unido, República Bolivariana de Venezuela. Información obtenida de la página web de UNCTAD ver: https://investmentpolicy.unctad.org/ international-investment-agreements (última consulta 20 de julio de 2019)

11 Brasil tiene firmados 8 Acuerdos de Cooperación y Facilitación de las Inversiones con Ios siguientes Estados: Angola, Chile, Colombia, Etiopía, Malawi, México, Mozambique, Suriname. Solo el Acuerdo con Angola está vigente (entró en vigor el 28/07/2017). Información obtenida de la página web de UNCTAD ver: https://investmentpolicy.unctad.org/ international-investment-agreements (última consulta 20 de julio de 2019) 
inversores extranjeros. En consecuencia, el Poder Ejecutivo retiró los tratados del Congreso y Brasil se convirtió en el único Estado del MERCOSUR y de América latina en no haber tenido nunca un TBI en vigor (Bas Vilizzio 2018: 49).

La importancia de este cambio,de los TBI al nuevo modelo, puede observarse en que "desde que Brasil firmó el Primer Acuerdo de Cooperación y Facilitación de las Inversiones (ACFI) en marzo de 2015, se han publicado varias traducciones del documento al inglés y diferentes análisis sobre sus aspectos más innovadores" (Morosini y Ratton Sánchez Badin 2015: 3). Así, Brasil, "es uno de los mayores receptores mundiales de IED, principalmente debido al gran tamaño de su mercado interno. Sin embargo, la necesidad de proteger sus crecientes inversiones en el exterior, lo llevó a reevaluar su política" (Herreros, 2018: 1).

No fue hasta el 2012, que la Cámara Brasileña de Comercio Exterior (CAMEX) emitió el mandato al Grupo Técnico de Estudios Estratégicos sobre Comercio Exterior (GTEX) para que trabajara - entre otros temas - en la redacción de un nuevo acuerdo de inversión que fuera sensible a las necesidades y preocupaciones brasileñas en el escenario económico internacional. En el contexto de las relaciones entre Brasil y África, el GTEX recomendó la creación de una nueva clase de acuerdo de inversión, bajo la dirección de la Secretaría de Comercio Exterior (SECEX) del Ministerio de Desarrollo, Industria y Comercio (MDIC). Esto dio un nuevo impulso al continuo pero lento proceso que comenzó con la negociación de los TBIs durante la década de 1990 (Morosini y Ratton Sánchez Badin, 2015: 3).

Así, el modelo del nuevo acuerdo, "estuvo listo a partir de 2013, cuando fue aprobada por CAMEX y luego propuesta a los Estados donde las empresas brasileñas estaban invirtiendo más habitualmente. Mozambique, Angola, México y Malaui fueron los primeros países en responder al ímpetu negociador de Brasil" (Morosiniy Ratton Sánchez Badin, 2015: 4). 
De esta manera los ACFI irrumpen en el escenario internacional captando la atención de la comunidad internacional como algo novedoso en su conjunto debido a la conjunción de dos aspectos:

Por una parte representan un giro importante en la política de una de las principales economías en desarrollo del mundo, integrante del G20 y del Grupo de los BRICS. Por otra parte, constituyen un marco regulatorio novedoso que se distingue de los Tratados Bilaterales de Inversión tradicionalmente negociados por los países desarrollados y que han sido la base de la gobernanza de la IED hasta ahora (Herreros y García Millán 2017: 28).

A continuación se analizará el Protocolo de Cooperación y Facilitación de Inversiones Intra-MERCOSUR que siguió en gran medida el modelo ACFI de Brasil.

\section{El protocolo de cooperación y facilitación de inversiones intra-Mercosur}

El 7 de abril de 2017 en el marco del Foro Económico Mundial que se celebró en Buenos Aires, los Ministros de Relaciones Exteriores de los países que integran el MERCOSUR adoptaron el Protocolo de Cooperación y Facilitación de las Inversiones Intra- MERCOSUR (Decisión 3/2017 del Consejo Mercado Común). ${ }^{12}$

Durante la XCIX Reunión Ordinaria del Grupo Mercado Común (22 y 23 de septiembre de 2015), Brasil presentó una propuesta para negociar un Protocolo sobre Cooperación y Facilitación de Inversiones Intra - MERCOSUR.

De acuerdo a lo señalado anteriormente, esta iniciativa de Brasil fue tratada en el Subgrupo de Trabajo $\mathrm{N}^{\circ} 12$ Sobre Inversiones del MERCOSUR y culminó con la adopción del Protocolo de Cooperación y Facilitación de las Inversiones Intra- MERCOSUR

\footnotetext{
12 Fue firmado por Argentina, Brasil, Paraguay y Uruguay. Venezuela está suspendido desde diciembre de 2016.
} 
(Decisión 3/2017 del Consejo Mercado Común) del 7 de Abril de 2017. El Protocolo Intra - MERCOSUR "sigue muy cercanamente la estructura y el contenido de los ACFI, con mínimas diferencias"(Herreros y García Millán, 2017:30). En ese orden de ideas, el Protocolo de Cooperación y Facilitación de Inversiones Intra - MERCOSUR "es una prueba del liderazgo regional de Brasil en esta temática” (Bas Vilizzio 2018, 57).

A continuación realizaremos una aproximación a sus principales disposiciones.

\section{a. Facilitación de las Inversiones}

Desde el punto de vista semántico, la facilitación de inversiones, conforme señala Singh, citado por Ghiotto "aparece como un término laxo e impreciso. Engloba acciones regulatorias, roles institucionales y procedimientos administrativos con el fin de facilitar la entrada, operación y salida de los inversores" (2017: 2). Luciana Ghiotto considera que "encontramos un nuevo modo de 'cooperación regulatoria' entre los aparatos regulatorios de los Estados” (2017:2). En ese sentido, Facilitación es un concepto que:

no incluye cláusulas de protección de las inversiones ni mecanismo de solución de controversias inversor-Estado (ISDS por su sigla en inglés). Incorpora en cambio términos como "transparencia", "previsibilidad" y "compromiso con las partes interesadas" para establecer un nuevo conjunto de reglas para la inversión extranjera a nivel multilateral (Ghiotto, 2017: 2).

Por este motivo se entiende que "las disposiciones sobre facilitación de las inversiones se avocan principalmente al acceso al mercado y predominan en la estructura de los ACFI" (Morosini y Ratton Sanchez Badin 2015: 3)

\section{b. Desarrollo Sustentable}

El nuevo Protocolo del MERCOSUR tiene como objetivo “...Promover la cooperación entre los Estados Partes con el fin 
de facilitar la inversión directa que viabilice el desarrollo sustentable de los Estados Partes" (Art. 1). De esta manera se consagra el desarrollo sustentable en correlato con su Preámbulo que establece "reconociendo el papel fundamental de la inversión en la promoción del desarrollo sustentable, en el crecimiento económico, en la reducción de la pobreza, en la creación de empleo, en la expansión de la capacidad productiva y en el desarrollo humano".

Esta consagración del desarrollo sustentable como objetivo en el Art. 1 y en el Preámbulo es importante. Al respecto Laborías señala "si bien cualquier preámbulo de un acuerdo internacional contiene necesariamente fórmulas amplias, que reflejan los grandes ejes de concordancia entre los negociadores, su lectura y análisis es de gran relevancia para precisar los objetivos fijados, a partir de los cuales se puede interpretar el instrumento en su totalidad" (2018:136). Laborías continúa citando a Newcombe y Paradell que "son auspiciosas las menciones al desarrollo sostenible dado que, en caso de controversia entre un inversor y el Estado anfitrión, permitirán enfocar la solución en dicho sentido" (2018: 137). En ese orden de ideas, Laborías concluye que

Dadas las características comentadas del Art. 1, si en caso de controversia una autoridad jurisdiccional debe remitirse a la justificación del Protocolo para determinar el alcance de las reglas de derecho vigentes entre un inversor y un Estado Parte, deberá realizar una fusión entre este artículo y el Preámbulo integrando ambos textos para comprender el real sentido del texto acordado en el MERCOSUR (2018, 139).

\section{c. Expropiaciones}

Una disposición que merece destacarse es la contenida en el Art. 6 que regula la expropiación directa y excluye la indirecta $^{13}$. Se considera que "en el Derecho Internacional hay un

\footnotetext{
13 Art. 6: (...) “6. Para mayor certeza, el presente Protocolo solo prevé la expropiación directa, en la cual una inversión es expropiada directamente mediante la transferencia formal del título o del derecho de dominio, y no cubre la expropiación indirecta".
} 
considerable grado de consenso sobre el criterio acerca de los requisitos que debe reunir una expropiación legal. La expropiación debe ser realizada: mediante ley, por causa de utilidad pública, no debe ser discriminatoria y se debe realizar el pago de una indemnización conforme al Derecho Internacional" (Lowe, 2007: 53).

Se debe distinguir la expropiación directa, referida anteriormente, de la indirecta. Esta última suele denominarse como expropiación de facto o medida equivalente a la expropiación.

En relación a la expropiación indirecta, Echaide señala que conceptos como el que las empresas sean indemnizadas no solo por las expropiaciones sino por las expectaciones legítimas de sus negocios o interpretaciones como que el tratamiento justo y equitativo incluya una obligación de estabilidad del clima legal para las inversiones, son creaciones pretorianas que pasan por sobre las decisiones soberanas de los Estados al momento de obligarse por los tratados que celebraron (2013:485).

\section{d. Libre Transferencia}

La libre transferencia está permitida, salvo por causales muy puntuales que la limitan a las derivadas de cumplimiento de sentencias judiciales, a laudos arbitrales o resoluciones administrativas firmes, procedimientos concursales, de quiebra, insolvencia o protección de los derechos del acreedor, cumplimiento de obligaciones laborales o tributarias, y prevención de lavado de dinero o de activos y de financiamiento de terrorismo. ${ }^{14}$

\footnotetext{
14 Artículo 9 - Transferencias

1. Los Estados Partes permitirán la libre transferencia de los fondos relacionados con la inversión realizada en su territorio por un inversionista de otro Estado Parte, a saber:

(a) la contribución inicial al capital o toda adición al mismo en relación con el mantenimiento o la expansión de esa inversión;

(b) los rendimientos directamente relacionados con la inversión;

(c) el producto de la venta o liquidación total o parcial de la inversión;
} 
Bernasconi - Osterwalder y Braunch consideran que en todo acuerdo de cooperación y facilitación de inversiones en el futuro se pueden incluir "situaciones relacionadas con la restricción de transferencias cuando existe crisis en la balanza de pagos debido a que los movimientos de capital pueden acarrear serias dificultades en la conducción macroeconómica y en particular en las políticas de tipos de cambio" (2015: 12).

\section{e. Responsabilidad Social Empresaria}

Un lugar importante ocupan las normas sobre Responsabilidad Social Empresaria-RSE (Art. 14) ${ }^{15}$.

(d) los pagos de cualquier préstamo, incluidos los intereses sobre el mismo, directamente relacionados con la inversión; y

(e) el importe de la indemnización, en caso de expropiación o el uso temporal de la inversión de un inversionista de otro Estado Parte por autoridades del Estado Parte Anfitrión. Cuando la indemnización se pague en bonos de la deuda pública al inversionista de otro Estado Parte, el mismo podrá transferir el valor de los ingresos de la venta de dichos bonos en el mercado.

2. Las transferencias se realizarán, a criterio del inversionista, en las monedas de los Estados Partes o en moneda libremente convertible conforme al tipo de cambio vigente en el mercado a la fecha de la transferencia, de acuerdo con el ordenamiento jurídico interno del Estado Parte Anfitrión.

3. No obstante lo establecido en este Artículo, un Estado Parte podrá condicionar 0 impedir una transferencia mediante la aplicación equitativa, no discriminatoria y de buena fe de las normas de su ordenamiento jurídico interno relativas a:

(a) procedimientos concursales, reestructuración de empresas, quiebra, insolvencia 0 protección de los derechos de los acreedores;

(b) cumplimiento de providencias judiciales, arbitrales o administrativas en firme;

(c) cumplimiento de obligaciones laborales o tributarias; 0

(d) prevención de lavado de dinero o de activos y de financiamiento de terrorismo.

15 "Artículo 14 - Responsabilidad Social Empresarial

Los inversionistas y sus inversiones se esforzarán por lograr el más alto nivel posible de contribución al desarrollo sustentable del Estado Parte Anfitrión y la comunidad local, a través de la adopción de un alto grado de prácticas socialmente responsable sobre la base de los principios y normas voluntarias establecidas en este Articulo

Los Inversionistas y sus inversiones deberán desarrollar sus mejores esfuerzos para cumplir con los siguientes principios y normas voluntarias para una conducta empresarial responsable y coherente con las leyes aplicadas por el Estado Parte Anfitrión: 
La RSE "plantea una mejora de la transparencia empresaria, la disciplina del mercado, el medio ambiente, la calidad de vida de clientes y consumidores, el bienestar de los empleados y sus familiares y la provisión de bienes públicos a la comunidad" (Hers, 2013: 596).

Laborías, en relación a la RSE señala que "lo primero que debe advertirse es que el mandato establecido respecto de los inversores es de difícil verificación, al utilizar la expresión se esforzarán, de ahí que sea identificable como una obligación de medios" (2018: 140).

\section{f. Potestades Reglamentarias del Estado}

Las facultades reglamentarias del Estado receptor se encuentran en el Art. 16 ${ }^{16}$. En el primer inciso se establece un ámbito que se puede señalar como que corresponde a la jurisdicción

Estimular el progreso económico, social y ambiental, con miras a lograr el desarrollo sustentable;

Respetar los derechos humanos de las personas involucradas en las actividades de las empresas, de conformidad con las obligaciones y los compromisos internacionales del Estado Parte Anfitrión

Promover el fortalecimiento de la construcción de las capacidades locales a través de una estructura de colaboración con la comunidad local

Fomentar el desarrollo del capital humano, en especial mediante la creación de oportunidades de empleo y facilitar el acceso de los trabajadores a la formación profesional

Abstenerse de buscar o de aceptar exenciones que no están establecidas en la legislación del Estado Parte Anfitrión, en relación con el medio ambiente, la salud, la seguridad, el trabajo, los incentivos financieros u otras cuestiones

Apoyar y mantener principios de buen gobierno corporativo y desarrollar y aplicar las buenas prácticas de gobierno corporativo

Desarrollar y aplicar prácticas de autorregulación y sistemas de gestión eficaces que promuevan una confianza mutua entre las empresas y la sociedad en la que se conducen las operaciones"

16 Artículo 16 - Disposiciones sobre Inversiones y Medio Ambiente, Asuntos Laborales y Salud

1. Nada de lo dispuesto en el presente Protocolo se interpretará como impedimento para que un Estado Parte adopte, mantenga o haga cumplir cualquier medida que considere apropiada para garantizar que las actividades de inversión en su territorio se efectúen de conformidad con la legislación laboral, ambiental o de salud en ese Estado Parte, siempre 
interna de los Estados. En esa área, un Estado Parte puede válidamente adoptar, mantener y hacer cumplir cualquier medida que se considere apropiada para garantizar que las actividades de inversión en su territorio se realicen de conformidad con la legislación laboral, ambiental o de salud en ese Estado Parte y se establece como límite a esta potestad la discriminación arbitraria o injustificable o una restricción encubierta. En el segundo inciso, se considera que no es apropiado estimular la inversión disminuyendo los estándares de su legislación laboral y ambiental o de sus medidas de salud en los Estados receptores, por lo tanto se garantiza que no disminuirán los estándares de su legislación laboral y ambiental o de sus medidas de salud para favorecer la recepción de inversiones extranjeras. Una disposición similar la encontramos en Tratado de Libre Comercio de América del Norte en donde "las Partes también reconocen que es inadecuado alentar la inversión mediante la flexibilización de cuestiones relacionadas con la salud (relaxing domestic bealth), seguridad o medio ambiente. En consecuencia, las Partes no deben renunciar o derogar dichas medidas ambientales para atraer inversiones (Art. 1114)" (Castillo Argañarás 2015: 399). Se está especificando un derecho a regular que puede ser definido como "el derecho soberano de los Estados a regular en busca del interés público - su espacio de políticas" (Morosini, 2018: 11).

En la Resolución 69/313 de Asamblea General de las Naciones Unidas que adopta en su Anexo la Agenda de Acción de Addis Ababa de la Tercera Conferencia de la Organización

y cuando esa medida no se aplique de manera que constituya un medio de discriminación arbitraria o injustificable 0 una restricción encubierta.

2. Los Estados Partes reconocen que no es apropiado estimular la inversión disminuyendo los estándares de su legislación laboral y ambiental o de sus medidas de salud. Por lo tanto, cada Estado Parte garantiza que no modificará o derogará, ni ofrecerá la modificación o la derogación de esta legislación para estimular una inversión en su territorio, en la medida que dicha modificación o derogación implique la disminución de sus estándares laborales 0 ambientales. Si un Estado Parte considera que otro(s) Estado(s) Parte(s) ha(n) ofrecido este tipo de incentivos, podrá solicitar consultas con ese(os) otro(s) Estado(s) Parte(s). 
de Naciones Unidas del Financiamiento para el Desarrollo del 17 de Agosto de 2015 se puntualizó "el objetivo de proteger y alentar las inversiones no debe afectar nuestra capacidad para lograr objetivos de política pública" (2015: 91).

Estas facultades del Estado receptor de la inversión es un punto crucial en la relación inversor - Estado anfitrión y numerosos arbitrajes se han realizado para interpretar esta cuestión; ya que "la actividad administrativa de regulación - denominada en este contexto el 'derecho a regular'- queda sujeto no solo a controles domésticos sino también a controles globales, especialmente, a través del arbitraje internacional de inversiones" (Hernández González 2016: 4). Este control mediante tribunales internacionales arbitrales en muchos casos limitó la potestad regulatoria del Estado saliendo perdedor en esta tensión entre el derecho a regular y los estándares de los tradicionales TBI.

\section{g. Gobernanza Institucional y Prevención de Controversias}

Un aspecto relevante del Protocolo es la cooperación entre Estados. Herreros y García Millán subrayan que "el pilar institucional del Protocolo se enfoca fuertemente en la cooperación entre los Estados e incorpora elementos similares al ACFI, como la creación de una Comisión para la aplicación y ejecución del acuerdo y la designación en cada país de una agencia o ministerio como Punto Focal Nacional u Ombudsman" (2017: 30). En ese sentido, la administración del Protocolo está en cabeza de una Comisión integrada por los representantes de los Estados Partes (Art. 17.1)

En virtud del Art. 18. 1 que establece que cada Estado Parte designa un Punto Focal Nacional u Ombudsman ${ }^{17}$. La principal

\footnotetext{
17 Artículo 18 - Puntos Focales u "Ombudsman" 1. Cada Estado Parte designará, de acuerdo a lo dispuesto en su ordenamiento jurídico interno, un Punto Focal Nacional u "Ombudsman" tendrá como principal responsabilidad el apoyo a los inversionistas de los otros Estados Partes en su territorio.

(a) En Argentina, el Punto Focal Nacional será la Subsecretaría de Comercio Exterior, dependiente de la Secretaría de Comercio del Ministerio de Producción.
} 
función es "apoyar a los inversionistas de los otros Estados Partes en su territorio" (Herreros y García Millán 2017: 30).

El Protocolo establece un procedimiento para prevención de controversias (Art. 23) y otro para solución de controversias (Art. 24). En el primer procedimiento, en el supuesto que un Estado se sienta vulnerado por una medida adoptada por otro Estado Parte, el primero puede iniciar un reclamo ante la Comisión mediante la presentación de un escrito donde conste:

i) indicación de los Estados Partes involucrados;

ii) enunciación preliminar del objeto de la diferencia;

iii) descripción de los antecedentes que dan origen a la diferencia;

iv) fundamentos jurídicos de la alegación de violación, con indicación precisa de las disposiciones aplicables del presente Protocolo; y

v) elementos de prueba de los hechos alegados, si correspondiere. (Art. 23)

La Presidencia de la Comisión la convocará a una reunión dentro de los treinta días de presentado el escrito por el cual se inició el presente mecanismo. A posterior la Comisión dispone de sesenta días para llegar a una solución.

En el caso que la controversia no pueda ser solucionada en los plazos estipulados o que el procedimiento de prevención se agote, las Partes involucradas pueden recurrir a los mecanismos de solución de controversias vigentes en el MERCOSUR (Art. 24)

El PCFI sigue a grandes líneas el esquema de los ACFI. En ese orden de ideas,

(b) En Brasil, el Ombudsman será el Ombudsman de Inversiones Directas en el ámbito de la Cámara de Comercio Exterior - CAMEX (c) En Paraguay, el Punto Focal Nacional será el Ministerio de Industria y Comercio.

(d) En Uruguay, el Punto Focal Nacional será el Ministerio de Economía y Finanzas.

2. Cada Estado Parte podrá modificar su Punto Focal designado en el presente Protocolo, debiendo en tal caso, comunicarlo por escrito a los otros Estados Partes a la mayor brevedad posible. Hasta que dicha comunicación se realice, las notificaciones realizadas al Punto Focal anterior serán válidas. 
Los tratados firmados por Brasil contemplan tres etapas sine qua non para la solución de controversias: en primer lugar, se exhorta a las Partes Contratantes a acudir a mecanismos no judiciales para la solución amistosa de la controversia, donde deberá nombrarse a un Defensor del Pueblo en cada Estado para que oficie como mediador. En segundo lugar, si la solución amistosa falla, la situación deberá ser remitida a un Comité Conjunto creado por ambas Partes. En tercer lugar, si la controversia no es resuelta ante dicho Comité, las partes podrán someter la misma a un Tribunal $a d$ hoc o a una institución arbitral permanente si así lo decidiesen por mutuo acuerdo (Cuestas Zamora 2015).

Un punto importante que se debe tener presente es "que no establecen el arbitraje entre inversionista y Estado. El principal fin del arbitraje entre Estados es determinar si el Estado receptor violó alguna de las disciplinas del acuerdo y, de ser así, recomiendan que el Estado ajuste o elimine la medida que no cumple con las exigencias" (Vieira Martins, 2017: 7). Se deja de lado la posibilidad de acudir al Centro Internacional de Arreglo de Diferencias en Materia de Inversiones (CIADI) del Banco Mundial.

Luego de analizado el nuevo Protocolo, y anteriormente el camino que nos condujo hacia él de manera conjunta con el protagonismo de Brasil, se realizan las conclusiones.

\section{Conclusiones generales}

Los tratados entre Estados sobre protección de las inversiones extranjeras fueron evolucionando con el transcurso del tiempo. Los TBI también se desarrollaron con el paso delos años, produciéndose en la actualidad una nueva generación de tratados. La irrupción de las empresas o corporaciones transnacionales fue un fenómeno que despertó y aceleró el debate sobre los aspectos relacionados a su protección jurídica en otras latitudes distintas a las de su origen.

Los ACFI -ideados por Brasil - fomentan un modelo cooperativo centrado en la facilitación de las inversiones extranjeras 
y la prevención de controversias creando un entorno propicio para aquellas mediante un mecanismo de gobernanza institucional propio.

Los Estados Parte del MERCOSUR aún tienen en vigor acuerdos relativos a protección de inversiones extranjeras entre ellos y con respecto a terceros Estados; por lo cual deberán plantearse si, o renegociarán, denunciarán ese modelo de tratados para tener una realidad compatible con el actual Protocolo, en caso de entrar en vigor.

Un punto favorable del Protocolo es el establecimiento del desarrollo sostenible como objetivo en su Art. 1 y estableciendo pautas de interpretación en el Preámbulo que repercutirán en la solución de las controversias internacionales. Excluir a expropiación indirecta es resguardar el derecho de los Estados a poder regular sobre aspectos que permitirán al Estado Anfitrión preservar sus derechos soberanos a establecer pautas sobre sus recursos naturales, ambiente, etc.

Las palabras o frases como "transparencia", "previsibilidad", "cooperación internacional", "facilitación" y "compromiso con las partes interesadas" receptadas en este nuevo tipo de tratados tienden a establecer los cimientos para la regulación de las inversiones extranjeras en el derecho internacional económico donde la cooperación entre Estados tendría un rol preponderante.

La incorporación de normas sobre RSE es un acierto, pero no deja de ser una obligación de medios; no obstante, es un avance sobre las grandes corporaciones dado que en el sistema de los TBI se focalizaba en gran parte solo en las obligaciones de los Estados.

El Protocolo está dentro de una nueva generación de tratados, implicando un cambio de paradigma. Este régimen relativo a las inversiones extranjeras podría lograr un adecuado sistema de protección para todas las partes involucradas en los negocios internacionales. Estos nuevos acuerdos de cooperación y facilitación de inversiones son recientes y hace falta 
tiempo para probarlos en su implementación, aunque el hecho que sea Brasil su principal impulsor es una señal debido a su importancia en el escenario de las inversiones extranjeras. En el supuesto de consolidarse el modelo e involucrar más Estados que adopten este esquema, estaríamos frente a un cambio de paradigma en el mecanismo que regula las relaciones Estado - inversor.

El nuevo Protocolo de Cooperación y Facilitación de las Inversiones Intra - MERCOSUR es una herramienta novedosa que regula las IED y se debe tener presente su Preámbulo como un anhelo cuando establece "la conveniencia de crear un mecanismo de dialogo técnico con iniciativas gubernamentales que contribuyan al aumento significativo de la inversión mutua”.

\section{Bibliografía general}

ARROYO PICARD, Alberto, GHIOTTO, Luciana (2017) "Brasil y la nueva generación de Acuerdos de Cooperación y Facilitación de Inversiones: análisis del Tratado con México" Relaciones Internacionales La Plata. Argentina, $\mathrm{N}^{\circ}$ 52: 39-54. Recuperado de https://doi.org/10.24215/23142766e001 (última consulta 17 de junio de 2019).

BAS VILIZZIO, Magdalena (2018) "De la Protección a la Facilitación de las Inversiones: Análisis Particular del Arbitraje de Inversiones en el MERCOSUR". Revista de la Secretaría del Tribunal Permanente de Revisión del MERCOSUR, Año 6, Agosto. $\mathrm{N}^{\circ}$ 12: 45-67. Recuperado de http://www.revistastpr. com/index.php/rstpr/article/viewFile/310/155177 (última consulta 17 de junio de 2019).

BERNASCONI-OSTERWALDER, Nathalie y Brauch, Martin Dietrich (2015) "Comparative Commentary to Brazil's Cooperation and Investment Facilitation Agreements (CIFAs) with Mozambique, Angola, Mexico, and Malawi",International Institute for Sustainable Development,Canadá. September. 2015: 1-17. Recuperado de https://www.iisd.org/sites/default/files/publications/commentary-brazil-cifas-acfis-mozambique-angolamexico-malawi.pdf (última consulta 17 de junio de 2019). 
CASTILLO ARGAÑARÁS, Luis Fernando (2015) "Arbitraje, expropiaciones y ambiente. La experiencia del Capítulo 11 del Tratado de Libre Comercio de América del Norte" Revista de la Secretaría del Tribunal Permanente de Revisión, Asunción. Marzo. Año 3. $\mathrm{N}^{\mathrm{o}}$ 5: 391-405. Recuperado de http://dx.doi. org/10.16890/rstpr.a3.n5.391 (última consulta 17 de junio de 2019).

CUESTAS ZAMORA, Edgard (2015) "Brasil y los Recientes Acuerdos de Cooperación y Facilitación de las Inversiones: ¿Un nuevo surgimiento de la Protección Diplomática?"Debate Global, Blog de la Academia Colombiana de Derecho Internacional. 20 de Diciembre de 2015. Recuperado de https://debateglobal. wordpress.com/2015/12/20/brasil-y-los-recientes-acuerdosde-cooperacion-y-facilitacion-de-las-inversiones-unresurgimiento-de-la-proteccion-diplomatica/ (última consulta 20 de junio de 2019)

ECHAIDE, Javier (2013)."Arbitraje sobre Inversiones y DDHH. El Caso del Derecho al Agua" América Latina en Movimiento, Agencia Latinoamericana de Información (ALAI). Ecuador. Año XXXVII- No 485: 5-8. Recuperado de https://www.alainet. org/sites/default/files/alai485w.pdf (última consulta 20 de junio de 2019)

GHIOTTO, Luciana (2017) "La Negociación sobre Reglas para la Facilitación Multilateral de las Inversiones: apuntes para la discusión”. Documento de Trabajo. TNI TransnationalInstitute. The Netherlands, 8p. Recuperado de https://www.tni.org/es/ publicacion/la-negociacion-sobre-reglas-para-la-facilitacionmultilateral-de-las-inversiones (última consulta 28 de enero de 2019).

HERNANDEZ GONZÁLEZ, José Ignacio (2017) "Regulación Económica y Arbitraje Internacional de Inversiones" Revista Electrónica de Direito RED, Fevereiro. $\mathrm{N}^{\circ}$ 1: 1-33. Recuperado de https://dialnet.unirioja.es/ejemplar/487939 (última consulta 28 de enero de 2019

HERREROS, Sebastián (2018) "Facilitación de inversiones: una puerta hacia la convergencia entre la Alianza del Pacífico y el MERCOSUR" Puentes, Volume 19, No 3. 5 de junio de 2018. Recuperado de https://www.ictsd.org/bridges-news/puentes/ 
news/facilitaci\%C3\%B3n-de-inversiones-una-puerta-hacia-laconvergencia-entre-la (última consulta 10 de enero de 2019).

HERREROS, Sebastián, GARCÍA-MILLAN, Tania (2017) Opciones para la Convergencia entre la Alianza del Pacífico y el Mercado Común del Sur (MERCOSUR). La regulación de la inversión extranjera directa. Serie Comercio Internacional. CEPAL. Naciones Unidas. 45 p. Recuperado de https://www.cepal.org/ es/publicaciones/42176-opciones-la-convergencia-la-alianzapacifico-mercado-comun-sur-mercosur-laaccesado 10 de enero de 2019.

HERS, Liliana (2013) "Responsabilidad Social Empresaria, Legitimidad y Derecho de la Concurrencia"XII Congreso Argentino de Derecho Societario y VIII Congreso Iberoamericano de Derecho Societario y de la Empresa. Tomo III. Universidad Argentina de la Empresa y Cámara de Sociedades Anónimas. Buenos Aires. pp. 595- 604

LABORIAS, Alexis Rodrigo (2018) "El Protocolo de Inversiones del MERCOSUR en el contexto del nuevo Derecho Internacional de las Inversiones Extranjeras" Revista de la Secretaría del Tribunal Permanente de Revisión del MERCOSUR, Año 6, Agosto. $\mathrm{N}^{\mathrm{o}}$ 12: 127-148. Recuperado de http://dx.doi.org/10.16890/ rstpr.a6.n12.p127 (última consulta 10 de marzo de 2019)

LOWE, Vaughan. 2007. Changing Dimensions of International Investment Law. University of Oxford, Faculty of Law. Legal Studies Research Paper Series. No 4.124 p.

MARCHINI, Jorge, Morales, Josefina, Roffinelli, Gabriela (2018) "Conflictos entre Estados Latinoamericanos y Empresas Transnacionales: los desafíos de la región frente a los tratados de inversión asimétricos" InvestmentTreaty News, $\mathrm{N}^{\circ} 2$, Tomo 9. International Institute for Sustainable Development (IISD). Geneve. Julio 30 de 2018. Recuperado de https://www.iisd. org/itn/es/2018/07/30/conflicts-between-latin-american-countries-and-transnational-corporations-the-challenges-of-theregion-in-the-face-of-asymmetrical-investment-treaties-jorgemarchini-josefina-morales-gabriela-roffinel/ (última consulta 12 de enero 2019)

MOROSINI, Fabio (2018) "Haciendo que el Derecho a Regular en el Derecho de las Inversiones trabaje para el Desarrollo. 
Reflexiones de las Experiencias de Sudáfrica y Brasil. Investment Treaty New, $N^{\circ}$ 2, Tomo 9 International Institute for Sustainable Development (ISSD. 30 de julio de 2018. Recuperado de http://isds.bilaterals.org/?haciendo-que-el-derecho-aregular\&lang=en (última consulta 12 de enero de 2019).

MOROSINI, Fabio, RATTON SÁNCHEZ BADIN, Michelle (2015). "El Acuerdo Brasilero de Cooperación y Facilitación de las Inversiones (ACFI) ¿Una nueva fórmula para los acuerdos internacionales de inversión?" Investment Treaty News, Tomo 6, International Institute for Sustainable Development (ISSD). $\mathrm{N}^{\mathrm{o}}$ 3: 3-5. Recuperado de https://www.iisd.org/sites/default/ files/publications/iisd-itn-agosto-2015-espanol.pdf (última consulta 11 de enero de 2019).

NACIONES UNIDAS, Asamblea General, Resolución 69/313, Agenda de Acción de Addis Abeba de la Tercera Conferencia Internacional sobre la Financiación para el Desarrollo (Agenda de Acción de Addis Abeba) adoptada el 27 de Julio de 2015. 17 de Agosto de 2015. Recuperado de https://unctad.org/meetings/ es/SessionalDocuments/ares69d313_es.pdf (última consulta 31 de enero de 2019)

SORNARAJAH, M. (2010) The International Law on Foreign Investment.Third Edition. Cambridge. UK

VANDEVELDE, Kenneth (1998) The political economy of bilateral investment treaty. The American Journal of International Law, Vol. 92, October

VIERA MARTINS, José Henrique (2017) "Acuerdos de Cooperación y Facilitación de Inversiones (ACFI) de Brasil y Últimos Avances". Investment Treaty News. International Institute for Sustainable Development, Junio. Recuperado de https://www. iisd.org/itn/es/2017/06/12/brazils-cooperation-facilitationinvestment-agreements-cfia-recent-developments-jose-henrique-vieira-martins/ (última consulta 20 de junio de 2019) 